\title{
Dermatoglyphics patterns in patients suffering from primary amenorrhea and control population
}

\author{
Jiwane S. ${ }^{1}$, Gajbhiye V. ${ }^{2}$, Jiwane R. ${ }^{3}$ \\ ${ }^{1}$ Sushil Jiwane, Assistant Profesor, Department of Anatomy, Gandhi Medical Collage Bhopal, India, \\ ${ }^{2}$ Vivekanand Gajbhiye, Professor, Department of Anatomy, RKDF Medical Collage and Research Centre, \\ Bhopal, India, ${ }^{3}$ Rekha Jiwane, Professor, Department of Physiology, RKDF Medical College and Research \\ Centre, Bhopal, India.
}

Address for Correspondence: Dr. Sushil Jiwane, Assistant Professor, Department of Anatomy, Gandhi Medical Collage Bhopal, India

\begin{abstract}
Background: Dermatoglyphics is branch of medical science, which deals with the study of epidermal ridges and their configuration on the palmer region of hand and finger and planter region of foot and toes. Inspection of skin ridges provide a simple, inexpensive means of information to determine whether a given patient could have a particular chromosomal defect. Amenorrhea is defined primary when menarche does not occur by the age of 16 years in a girl with complete secondary sexual development. In the present study an attempt has been made to correlate primary amenorrhea and dermatoglyphics. Method: 40 normal females with primary amenorrhea were taken as case and 40 normal females with normal menstrual cycle were taken for study. Dermatoglyphic prints were obtained using ink method. Result: The mean value of atd angle shows statistically significant increase in patients than that of controls. Frequency of thenar/ ID 1 pattern, ID2area, ID3area, IDarea in a both right and left hands of primary amenorrhea patients and in control is insignificant. Similarly, there is increased frequency of hypothenar area pattern in patients as compared to controls in left hand, which is found to be statistically significant, Conclusion: Primary amenorrhoea and Dermatoglyphics, both have the suspected multifactorial (genetic and environmental) aetiologies. Dermatoglyphics, due to their suspected genetic aetiology. use for prognosis of disease and also the identification of people with the genetic predisposition to develop certain disease or early onset of symptoms.
\end{abstract}

Keywords: Primary amenorrhea, Dermatoglyphics, atd angle, Hypothenar area.

\section{Introduction}

The term Dermatoglyphics has its origin from Greek words, derma means skin and glyphic means carvings [1]. It gives the impression that something has been carved out of the skin [2]. Cummins in the year 1926 coined the term dermatoglyphics to this field of science and is regarded as the "Father of Dermatoglyphics" [3]. Dermatoglyphics is branch of medical science, which deals with the study of epidermal ridges and their configuration on the palmer region of hand and finger and planter region of foot and toes. They are completely formed by week 21 of intrauterine development and, furthermore, totally resistant to any external

Manuscript received: $30^{\text {th }}$ October 2017

Reviewed: $9^{\text {th }}$ November 2017

Author Corrected: $18^{\text {th }}$ November 2017

Accepted for Publication: 24 $4^{\text {th }}$ November 2017 factor, remaining unchanged until the end of a person's life and hence used for personal identification [4]. Dermatoglyphics are patterns observed on the epidermis on the fingers, palms, and soles. Inspection of skin ridges therefore promised to provide a simple, inexpensive means of information to determine whether a given patient could have a particular chromosomal defect [5].

Dermatoglyphics is in use as a diagnostic tool in genetic or chromosomal disorders as well as in clinical conditions with genetic etiology. WHO Annual reports 1982 and 1985 have estimated that $15 \%$ of the human population is infertile and that amenorrhea is the 6th major cause of female infertility [6]. Amenorrhea is classified as primary 
and secondary according to its occurrence before or after menarche, respectively [7]. Amenorrhea is defined primary when menarche does not occur by the age of 16 years in a girl with complete secondary sexual development, or by the age of 14 years in a girl without secondary sexual

\section{Material and Methods}

A prospective study was designed to collect the palmar and finger prints of females with primary amenorrhea. Place of study: study was conducted in department of Anatomy jawahar lal Nehru medical collage sawangi after taking ethical clearance. Inclusion criteria: 80 Female subjects of 17 to $25 \mathrm{y}$ of age groups attending the Obstetrics and Gynecology OPD and patients admitted in the Obstetrics and Gynecology ward of tertiary care hospital and teaching institute of central India were included in the study. Out of these females 40 females were suffering from primary amenorrhea were taken as case and 40 normal. Married females up to the age of 25 years who had given birth to at least one live child without the history of miscarriages or genetic abnormalities was taken as control. Exclusion criteria: Females before puberty, Antenatal females, Lactating females. Known case of chromosomal abnormalities like Turner syndrome. Were excluded from study. For all the subjects informed consent was taken in their local language along with detailed history before starting the procedure. All the records were maintained. Method: Dermatoglyphic prints were obtained from OPD and indoor patients using ink method described by Cummins and Midlo [4] and as per guidelines by American Association of Dermatoglyphics [8] analysis of palmer and finger prints were done in department of Anatomy.

Statistical analysis was done by Chi-square test using statistical software SPSS Version 17.00.

Data analyzed was

1. 'atd' angle

2. Inter digital pattern
a. Thenar / Inter digital area $1\left(\mathrm{Th} / \mathrm{ID}_{1}\right)$
b. $\mathrm{ID}_{2}$
c. $\mathrm{ID}_{3}$
d. $\mathrm{ID}_{4}$

3. Hypothenar area

'atd' angle: It is the most widely used method in interpreting the position of axial triradius. It is formed by lines drawn from digital triradius 'a' to the axial triradius' and from axial triradius' to the digital triradius ' $d$ '. In case of more than one axial triradii the widest 'atd' angle is counted. The more distal the position of $\mathrm{t}$, larger is the 'atd' angle. Atd angle averages about $48^{\circ}$ among the normal individuals. Atd angle is measured in adducted palm. The abducted palm gives more measurement by $10^{\circ}$. The instruction for determining the atd angle of the palm was given by Panrose in 1954 [9].

The atd angles were compared and assessed for increase or decrease in mean frequencies between the groups [10].

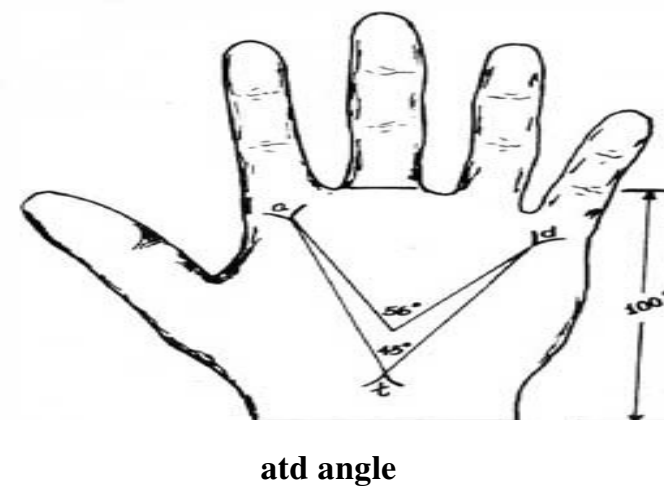


Thenar and first interdigital area (Th/ID $)$ : These two areas are closely related anatomically. In dermatoglyphic analysis they are usually considered as one area labeled thenar/ first interdigital (Th/ID $)_{1}$. In most cases there is no pattern in $\mathrm{Th} / \mathrm{ID}_{1}$ area but the ridges follow a mild curve around the base of the thumb.

Second, Third and Forth interdigital areas: These areas are found in the distal region of the palm in the region of heads of metacarpal bones.

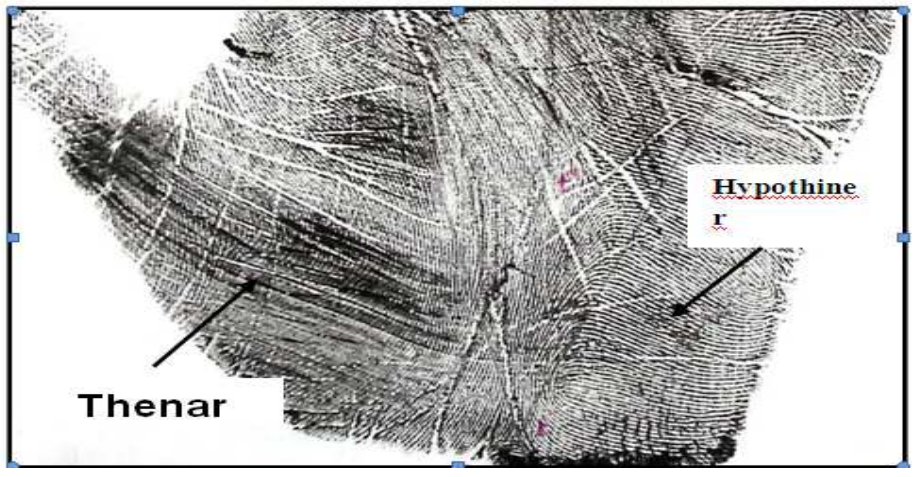

Hypothenar area: True pattern commonly present in the hypothenar area patterns are whorls, loops and tented arches. While simple arch, vestige, open fields can occur. Arches are the most frequent patterns in the hypothenar area. Open fields are rare in this area. Presence of two configurations can be expressed by dual configurations, the distal configuration being written first. The triradius or triradii close to the palmar axis are termed as AXIAL TRIRADII ( $\mathrm{t}$ ) symbol $\mathrm{t}$, $\mathrm{t}$ ' and $\mathrm{t}$ " are used to designate the position of these triradii in the proximal distal direction on the palm.

$\mathrm{t}$ - Axial triradii found in the proximal region of palm, near the wrist crease.

t"- triradius situated near the centre of palm,

t'- intermediate triradii-situated between t" and t.

Statistical Analysis: The data was analyzed statistically by using Chi-Square Test.

\section{Results}

Table No.-1: Showing means value of 'atd' angle in right and left hand of Patients of primary amenorrhea and controls.

\begin{tabular}{|c|c|c|c|c|c|}
\hline \multirow{2}{*}{ Side of hand } & \multicolumn{5}{|c|}{ 'atd' angle (degrees) } \\
\cline { 2 - 5 } & \multicolumn{2}{|c|}{ Patients } & \multicolumn{2}{c|}{ Controls } \\
\cline { 2 - 6 } & Mean & S.D. & Mean & S.D. & \\
\cline { 2 - 6 } & 44.15 & 3.50 & 38.95 & 4.12 & $6.07(\mathrm{p}=0.000)$ \\
\hline Right & 46.02 & 4.31 & 40.80 & 3.89 & $5.68(\mathrm{p}=0.000)$ \\
\hline Left & 45.08 & 4.01 & 39.87 & 4.09 & $8.12(\mathrm{p}=0.000)$ \\
\hline
\end{tabular}

Right Hand $\quad: \quad z=6.07, p$-value $=0.00(\mathrm{p}<0.05) \quad$ Statistically Significant

Left Hand $\quad: \quad z=5.68, p$-value $=0.00(\mathrm{p}<0.05) \quad$ Statistically Significant

Total $\quad: \quad \mathrm{z}=8.12, \mathrm{p}$-value $=0.00(\mathrm{p}<0.05)$ Statistically Significant

The above table shows that atd angle in right hand of primary amenorrhea is $44^{\circ}$ as compared to $38^{\circ}$ of control group. There is increase in atd angle due to shift of axial triradius, and it is statistically significant. Left hand also shows the increase in atd angle than controls. The mean value of atd angle shows statistically significant increase in patients than that of controls. 
Original Research Article

Table No.-2: Frequency of Thenar / $\mathrm{ID}_{1}$ area pattern in right and left hand of patients of primary amenorrhea and controls.

\begin{tabular}{|c|c|c|c|c|c|}
\hline Side of hand & Patients & Controls & $\mathbf{X}^{\mathbf{2}}$ & $\mathbf{p}$ - value & Inference \\
\hline Right & $16(48.0 \%)$ & $17(42.5 \%)$ & 0.05 & 0.82 & $\begin{array}{c}\text { Non Significant } \\
(\mathrm{p}>0.05)\end{array}$ \\
\hline Left & $19(47.5 \%)$ & $20(50.0 \%)$ & 0.05 & 0.82 & $\begin{array}{c}\text { Non Significant } \\
(\mathrm{p}>0.05)\end{array}$ \\
\hline
\end{tabular}

The above table shows frequency of thenar / $\mathrm{ID}_{1}$ pattern in both right and left hands of primary amenorrhea patients. In right hand there is decreased frequency of $I_{1}$ area pattern in patients i.e $16(48.0 \%)$ as compared to controls i.e. 17 (42.5\%), which is non-significant statistically ( $\mathrm{p}>0.05)$.

Similarly, in left hand there is decreased frequency of thenar pattern is observed in patients i.e. $19(47.5 \%)$ as compared to controls i.e. $20(50.0 \%)$ and it is non-significant statistically $(\mathrm{p}>0.05)$.

Table No.-3: Frequency of $\mathrm{ID}_{2}$ area pattern in right and left hand of patients of primary amenorrhea and controls.

\begin{tabular}{|c|c|c|c|c|c|}
\hline Side of hand & Patients & Controls & $\mathbf{X}^{\mathbf{2}}$ & $\mathbf{p}$ - value & Inference \\
\hline Right & $21(52.5 \%)$ & $19(47.5 \%)$ & 0.20 & 0.65 & $\begin{array}{c}\text { Non Significant } \\
(\mathrm{p}>0.05)\end{array}$ \\
\hline Left & $20(50.0 \%)$ & $21(52.5 \%)$ & 0.05 & 0.82 & $\begin{array}{c}\text { Non Significant } \\
(\mathrm{p}>0.05)\end{array}$ \\
\hline
\end{tabular}

The above table shows that there is increased frequency of $\mathrm{ID}_{2}$ area pattern in patients i.e. $21(52.5 \%)$ as compared to controls i.e. $19(47.5 \%)$ in right hand, which is found to be statistically non-significant ( $p>0.05)$.

Similarly, there is decreased frequency of $\mathrm{ID}_{2}$ area pattern in patients i.e. $20(50.0 \%)$ as compared to controls i.e. $21(52.5 \%)$ in left hand, hence it is found to be statistically non-significant ( $\mathrm{p}>0.05)$.

Table No.-4: Frequency of $\mathrm{ID}_{3}$ area pattern in right and left hand of patients of primary amenorrhea and controls.

\begin{tabular}{|c|c|c|c|c|c|}
\hline Side of hand & Patients & Controls & $\mathbf{X}^{2}$ & $\mathbf{p}$ - value & Inference \\
\hline Right & $24(60.0 \%)$ & $22(55.0 \%)$ & 0.20 & 0.65 & $\begin{array}{c}\text { Non Significant } \\
(\mathrm{p}>0.05)\end{array}$ \\
\hline Left & $23(57.5 \%)$ & $25(62.5 \%)$ & 0.20 & 0.64 & $\begin{array}{c}\text { Non Significant } \\
(\mathrm{p}>0.05)\end{array}$ \\
\hline
\end{tabular}

The above table shows that there is less increased frequency of $\mathrm{ID}_{3}$ area pattern in patients i.e. $24(60.0 \%)$ as compared to controls i.e. 22 (55.0\%) in right hand, which is statistically non-significant ( $\mathrm{p}>0.05)$.

Similarly, there is decreased frequency of $\mathrm{ID}_{3}$ area pattern in patients i.e. $23(57.5 \%)$ as compared to controls i.e. $25(62.5 \%)$ in left hand. It is statistically non-significant $(\mathrm{p}>0.05)$.

Table No.- 5: Frequency of $\mathrm{ID}_{4}$ area pattern in right and left hand of patients of primary amenorrhea and controls.

\begin{tabular}{|c|c|c|c|c|c|}
\hline Side of hand & Patients & Controls & $\mathbf{X}^{2}$ & $\mathbf{p}$ - value & Inference \\
\hline Right & $21(52.5 \%)$ & $20(50.0 \%)$ & 0.05 & 0.82 & $\begin{array}{c}\text { Non Significant } \\
(\mathrm{p}>0.05)\end{array}$ \\
\hline Left & $18(45.0 \%)$ & $19(47.5 \%)$ & 0.05 & 0.82 & $\begin{array}{c}\text { Non Significant } \\
(\mathrm{p}>0.05)\end{array}$ \\
\hline
\end{tabular}


The above table shows that there is less increased frequency of $\mathrm{ID}_{4}$ area pattern in patients i.e. $21(52.5 \%)$ as compared to controls i.e. $20(50.0 \%)$ in right hand, which is statistically non-significant ( $>0.05)$. Similarly, there is decreased frequency of $\mathrm{ID}_{4}$ area pattern in patients i.e. $18(45.0 \%)$ as compared to controls i.e. 19 $(47.5 \%)$ in left hand. It is statistically non-significant $(\mathrm{p}>0.05)$.

Table No.- 6: Frequency of hypothenar area pattern in right and left hand of patients of primary amenorrhea and controls.

\begin{tabular}{|c|c|c|c|c|c|}
\hline Side of hand & Patients & Controls & $\mathbf{X}^{\mathbf{2}}$ & $\mathbf{p}$ - value & Inference \\
\hline Right & $26(65.0 \%)$ & $19(47.5 \%)$ & 2.48 & 0.11 & $\begin{array}{c}\text { Non Significant } \\
(\mathrm{p}>0.05)\end{array}$ \\
\hline Left & $29(72.5 \%)$ & $18(45.0 \%)$ & 6.24 & 0.01 & $\begin{array}{c}\text { Significant } \\
(\mathrm{p}<0.05)\end{array}$ \\
\hline
\end{tabular}

The above table shows that there is slightly increased frequency of hypothenar area pattern in patients i.e. 26 $(65.0 \%)$ as compared to controls i.e. $19(47.5 \%)$ in right hand, which is statistically non-significant $(\mathrm{p}>0.05)$.

Similarly, there is increased frequency of hypothenar area pattern in patients i.e.29 (72.50\%) as compared to controls i.e.18 (45.0\%) in left hand, which is found to be statistically significant.

\section{Discussion}

The dermatoglyphics has become a valuable tool in medico legal, anthropological and various medical genetic disorders. This science is correlated with a variety of chromosomal and developmental defects and certain clinical disorders which have strong genetic and hereditary background. The occurrence of a set of characteristic dermatoglyphics features (DGFs) in Down's syndrome patients like single transverse palm crease, wide atd angle in palm, increased occurrence of ulnar loops and a corresponding decrease in the frequency of the other three patterns i.e. whorl, radial loop and arch. Dermatoglyphics assumed a role in medical research and diagnostic investigation and have gained the relationship between epidermal ridge configurations and specific medical disorders [11].

In clinical genetics, dermatoglyphics studies are of primary importance in chromosome abnormalities, limb formation. In many disorders, both chromosomal and non-chromosomal, aneuploidy and polyploidy syndromes dermatoglyphics have been successfully employed [12]. The dermatoglyphics configurations in amenorrhea are not widely studied. So the present study has been undertaken to find out the co-relation of dermatoglyphic parameters in amenorrhea cases and controls.

atd Angle : The atd angle is formed by a line drawn from triradius "a" to tiradius " $\mathrm{t}$ " with a line from triradius " $t$ " to triradius "d". When more than one triradius are present, the most distal point is used to measure the atd angle. Dermatoglyphic features of atd angle: atd angle shows statistical significance in both hands (right and left hand) in present study i.e. atd angle is increased in primary amenorrhea patients as compared to controls which are an important parameter.

Mutalik G. S et al in their study noted that atd angle in right and left hand shows significant increase in patients of primary amenorrhea when compared with normal [13]. Present study co-relates with their observations.

Interdigital areas:

Thenar / $\mathrm{ID}_{1}$ area: In primary amenorrhea patients the pattern frequency is statistically non-significant in both right and left hands as compared to controls.

$\mathrm{ID}_{2}$ area: The pattern frequency is non-significant in patients of primary amenorrhea and control

$\mathrm{ID}_{3}$ area: The area pattern frequency in both the hands of primary amenorrhea patients and controls does not show any significant differences.

$\mathrm{ID}_{4}$ area: In both the hands area pattern frequency in primary amenorrhea patients is non-significant as compared to controls.

Hypothenar area: The area pattern frequency is significantly increased in left hand of primary amenorrhea patients as compared to controls. 
Original Research Article

Meenakshi S., Balasubramanyam V. and Sayee Rajangam [6] in their study observed significant increase of patterns in hypothenar area of left side in primary amenorrhea patients as compared to controls. It was found to be statistically significant. In our study we also got significant increase of patterns in hypothenar area of left side in primary amenorrhea patients as compared to controls.

\section{Conclusion}

There is a statistically significant difference in the dermatoglyphic patterns in amenorrhea patients as compared to controls.atd angle and hypothiner areas in amenorrhea patient is more significant as compare to control. Interdigital areas are not significant in both groups.

\section{What this study adds to existing knowledge}

Dermatoglyphics is use as a supportive diagnostic tool in genetic or chromosomal disorders as well as in clinical conditions with genetic etiologies. Primary amenorrhoea and Dermatoglyphics, both have the suspected multifactorial (genetic and environmental) aetiologies. Thus, the utility of dermatoglyphics is not to diagnosis, but to prognosis of disease and also the identification of people with the genetic predisposition to develop certain disease or early onset of symptoms. Hence exclusive study is needed.

Funding: Nil, Conflict of interest: None Permission of IRB: Yes

\section{References}

1. Gibbs RC. Fundamentals of dermatoglyphics. Arch Dermatol. 1967 Dec;96(6):721-5.

2. Sadler TW. Integumentary system. In: Langman's Medical embryology. 11th ed. Philadelphia, USA: Lippincott Williams and Wilkins; 2010. p. 346.

3. Mulvihill JJ, Smith DW. The genesis of dermatoglyphics. J Pediatr. 1969 Oct;75(4):579-89.
4. Cummins H, Midlo C. Fingerprints, Palms and Soles: An Introduction to Dermatoglyphics; Dover Publications Inc: New York, NY, USA, 1961.

5. Sridevi NS, Delphine Silvia CR, Kulkarni R, Seshagiri C. Palmar dermatoglyphics in carcinoma breast of Indian women. Romanian Journal of Morphology \& Embryology. Romanian Journal of Morphology \& Embryology. 2010;51(3):547-50.

6. Meenakshi S, Balasubramanyam $\mathrm{V}$ and Rajangam S. Dermatoglyphics in amenorrheaqualitative analysis. J Obstet Gynecol of India. 2006; 56 (3):250-54

7. Practice Committee of American Society for Reproductive Medicine. Current evaluation of amenorrhea. Fertil Steril. 2008 Nov; 90 (5 Suppl): S219-25. doi: 10.1016/j.fertnstert. 2008.08. 038.

8. Reed T, Meier R. Taking dermatoglyphic prints - a self instruction manual. Sponsored by the American Association of Dermatoglyphics. 1990

9. Ellor CS. Dermatoglyphics in schizophrenia. I. Qualitative aspects. Br J Psychiatry. 1968 Nov;114 (516): 1387-97.

10. Holt SB. Epidermal ridge-counts. Coll Antropol. 1979; 3(1):97-106.

11. Cummins H, Midlo C. Fingerprints, Plams and soles. An introduction to dermatoglyphics. Philadalphia. Blakiston.;1949.

12. Temtamy S, Mckusick VA: Synopsis of hand malformations with particular emphasis on genetic factors. In Bergsma D(ed):"Limb malformation" White Plains.NY The National Foundation-March of Dimes. BD:OAS; 1969; 5(3): 125-184. (S)

13. Mutalik GS, Lokhandwala VA, Anjeneyulu R. Dermatoglyphical findings in primary amenorrhea. J Obstet Gynecol of India .1968;18:738-43.

\section{How to cite this article?}

Jiwane S, Gajbhiye V, Jiwane R. Dermatoglyphics patterns in patients suffering from primary amenorrhea and control population. Int J Med Res Rev 2017;5(11):962-967.doi:10.17511/ijmrr. 2017.i11.08 